\title{
Assay of Rice Botanical And Biological Samples For Cadmium By Radio Chemical Displacement
}

\author{
K.Aruna* and N.Venkatasubba Naidu \\ Department Chemistry, Sri Venkateswara University, Tirupati - 517502, India
}

\begin{abstract}
The determination of cadmium in rice by radiochemical displacement is the main objective of the present work. Cadmium was preconcentrated and separated from coexisting ions by anion exchange resin. Optimum absorption and elution condition were studied. The absorption of cadmium on the resin was obtained by using $2 \mathrm{M} \mathrm{HCl}$. The eluting condition of cadmium was using $8 \mathrm{M}$ ammonia solution with the eluting efficiency of $96 \%$. Cd enriched was then analyzed by the displacement of labeled $\mathrm{Zn}$ from $\mathrm{Zn}$ : PAN complex. The detection limit was $6 \mu \mathrm{kg}^{-1}(n=5)$
\end{abstract}

\section{Introduction}

Cadmium is one of the main elemental pollutants in the environment due to its increased utilization in the industry and atmosphere. Its toxicology is hazardous for aquatic, animal and plant life. Food is a pathway of contamination. In man or animal the metal is mainly accumulated in kidney and liver with long biological half life. $(1,2)$

Separation of inorganic ions by ion exchange chromatography technique is often employed in various analytical techniques. Numerous separation procedures are almost exclusively based on the use of mono functional ion exchange, mostly strong basic and strong acidic ion exchange resin $(3,4,5,6)$.

The development of trace element analysis techniques to determine trace element is very important for analyzing various biological materials have gradually stimulated the interest of biological, environmental behavior of trace elements, especially while evaluating the extent of assure sufficient accuracy for cadmium determination at trace concentration level, namely AAS, ICP-AES and ICP-MS. Radiochemical displacement has not utilized for the determination of trace elements in general and cadmium in particular.

The present paper describes the preconcentration on an anion exchange column and determination of cadmium in rice by radiochemical displacement reaction :

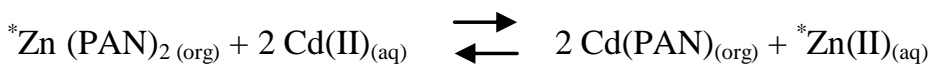

In the above reaction ${ }^{*}$ indicates the radio chemically labeled species and from the knowledge of the original activity of the complex and the activity released by cadmium, the amount of cadmium could be ascertained.

\section{Experimental}

Standard solutions of Cd were prepared by dissolving appropriate amounts of $\mathrm{CdO}$ (Merck) $99.99 \%$ $\mathrm{w} / \mathrm{w}$ in $5 \%(\mathrm{v} / \mathrm{v}), \mathrm{HNO}_{3}$ (Merck). The calibration standard solutions were prepared by diluting cadmium standard solutions in the range from $5 \mu \mathrm{g} / \mathrm{mL}$ to $25 \mu \mathrm{g} / \mathrm{mL}$.

${ }^{65} \mathrm{Zn}$ tracer was obtained from M/s Isotope Group, Bhabha Atomic Research Centre, Mumbai, with a specific activity of $37 \mathrm{MBq} / \mathrm{g} \mathrm{Zn}$, in the form of $\mathrm{ZnCl}_{2}$ in dil. $\mathrm{HCl}$.

Borate buffers were prepared in the $\mathrm{pH}$ range $4-7.5$.

$2 \times 10^{-4} \mathrm{M}$ Pan (Reanal) was prepared in Methanol.

Preparation of ${ }^{65} \mathrm{Zn}$ labeled $\mathrm{Zn}$ :PAN complex, the radio reagent, in chloroform was prepared as reported earlier (7)

Radioactivity measurements were made with a well type $\mathrm{NaI}(\mathrm{Tl})$ detector.

Sample Preparation: $1.0 \mathrm{~g}$. of sample was weighed in small polyethylene bags, pre-cleaned with nitric acid. The standard solutions were made from cadmium stock solution. The samples and standards were digested with $30 \mathrm{~mL}$ conc. $\mathrm{HNO}_{3}$ and evaporated to dryness, added $10 \mathrm{~mL} \mathrm{HClO} 4(72 \% \mathrm{w} / \mathrm{w})$ and evaporated to dryness, added $10 \mathrm{~mL} 30 \% \mathrm{H}_{2} \mathrm{O}_{2}$ solution and $10 \mathrm{~mL} 2 \mathrm{M} \mathrm{HCl}$ and evaporated to dryness, then dissolved in $1 \mathrm{~mL} 2 \mathrm{M}$ $\mathrm{HCl}$, and load through the anion exchange column with Dowex 1-X8 resin (Chloride form 100-200 mesh). The cadmium is retained in the resin. The sodium and ion interferences are eliminated by washing with $10 \mathrm{~mL}$ of 2

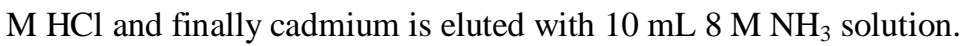


Adsorption and Desorption : The maximum adsorption of cadmium on the resin when using $2 \mathrm{M}$ $\mathrm{HCl}$ was $95.2 \%$ Elution efficiency of cadmium from the column using $10 \mathrm{~mL}$ of $8 \mathrm{M} \mathrm{NH}_{3}$ solution was $95.92 \%$ as shown in Figure 1.

Displacement of ${ }^{65} \mathrm{Zn}$ from labeled $\mathrm{Zn}:$ PAN

Effect of $\mathbf{p H}: \mathbf{3} \mathbf{~ m L}$ of labeled $\mathbf{Z n}$ : PAN was taken in a series of equilibration tubes containing $20 \mu \mathrm{g}$ $\mathrm{Cd}$ at $\mathrm{pH}$ values ranging from $4.5-7.0$. The volume of the aqueous phase was maintained at $10 \mathrm{~mL}$ in all the cases. The contents of the tubes were equilibrated for $4 \mathrm{~min}$. and the activity of $1 \mathrm{~mL}$ of the aqueous phase was measured to ascertain the amount of $\mathrm{Zn}$ displaced. Blank values were obtained under similar conditions without added $\mathrm{Cd}$ and the measured values were corrected for blank. (Fig.2). Of the solvents, chloroform, carbon tetrachloride, benzene, toluene, MIBK and nitrobenzene, chloroform was best suited for the displacement reaction.

The displacement of $\mathbf{Z n}$ from its $\mathbf{Z n}$ : PAN complex was maximum at $\mathrm{pH} 5.5$ and falls off rapidly with increase in $\mathrm{pH}$ and negligible over $\mathrm{pH} 7 . \mathrm{pH} 5.5$ was selected for the further studies.

Calibration : Cadmium solutions containing $5-30 \mu \mathrm{g}$ of $\mathrm{Cd}$ were taken and $\mathrm{pH}$ adjusted to 5.5 and the volume adjusted to $10 \mathrm{~mL}$. $3 \mathrm{~mL}$ of the radioreagent was added and equilibrated for $3 \mathrm{~min}$. Blank values were obtained with solutions without the addition of cadmium. A plot of the corrected activities against the amount of $\mathrm{Cd}$ served as calibration. (Fig. 3)

Determination : Aliquots of sample solutions enriched were treated in a similar way with radioreagent solution. From the activity of ${ }^{65} \mathrm{Zn}$ released the cadmium content of the sample was evaluated with the aid of the calibration graph.

Detection limit, precision and correlation coefficient ( $r)$ : Detection limit [12] is defined as 3 times the standard deviation of the blank sample. The detection limit, precision and correlation coefficient $(r)$ of calibration curve $(2-25 \mu \mathrm{g} / \mathrm{mL})$ were determined for the proposed method. The results are summarized in Table. 1.

Accuracy: The reliable approach for assessment of the accuracy in rice analysis can be applied to cadmium which reference values are available in the same matrix. The result for the determination of cadmium in Table 2 is good agreement with the Certified Reference Material (CRM).

Rice samples : Rice samples were collected periodically from selected sources. the samples and standards were digested with $30 \mathrm{~mL}$ conc. $\mathrm{HNO}_{3}$ and evaporated to dryness, added $10 \mathrm{~mL} \mathrm{HClO}_{4}(72 \% \mathrm{w} / \mathrm{w})$ and evaporated to dryness, added $10 \mathrm{~mL} 30 \% \mathrm{H}_{2} \mathrm{O}_{2}$ solution and $10 \mathrm{~mL} 2 \mathrm{M} \mathrm{HCl}$ and evaporated to dryness, then dissolved in $1 \mathrm{~mL} 2 \mathrm{M} \mathrm{HCl}$, and load through the anion exchange column with Dowex 1-X8 resin (Chloride form 100-200 mesh). The cadmium is retained in the resin. The sodium and ion interferences are eliminated by washing with $10 \mathrm{~mL}$ of $2 \mathrm{M} \mathrm{HCl}$ and finally cadmium is eluted with $10 \mathrm{~mL} 8 \mathrm{M} \mathrm{NH}_{3}$ solution. The eluent was made to the required volume. Aliquots of the solution were adjusted to the specified conditions for the radiochemical displacement reaction, and the cadmium content was evaluated from the calibration plot. (Table 3)

Urine samples : A preliminary validation of the possible use of the optimized method for measuring metal ions in urine was performed, using spiked samples and standards. Samples of $50 \mathrm{ml}$ were used for the determinations. Linear standard curves (extracted) over the range of $1,1.5$, and $2 \mu \mathrm{g}$ were obtained each day $(n=6)$ with a correlation coefficient of 0.995 or greater. The day-to-day and within-day relative standard deviation of the method was investigated by spiking urine sample with Cd. Table 4.. shows the results obtained from this experiment.

Botanical and biological samples : The current literature survey on direct determination of trace elements in biological and botanical samples failed to demonstrate some specific features of this technique that can be used in plant physiology studies. Alder et al. (8) measured the distribution of 13 trace elements along the length of individual hairs by direct furnace atomization of $1 \mathrm{~cm}$ segments and measurement of atomic absorption.

Further, In the present study, cadmium was also measured in some botanical samples and also scalp hair of tannery workers and children.

\section{Sample collection and preparation procedures}

Botanical samples: Depending on the nature of the study, collection of botanical samples was performed either by biopsy or the whole mass of a particular plant tissue was taken for analysis. In the latter case the plant material was dried at $105^{\circ} \mathrm{C}$. pulverized by grinding and analysed by slurry sample introduction. Biopsy sampling of botanical material was performed using special tools. Discs $6 \mathrm{~mm}$ in diameter were cut from each plant leaf using a punch made of aluminium. Cuttings from the root tissue were obtained in a similar way. A teflon plate served as a support. In metal distribution studies the biopsy samples (leaf discs or root cuttings) were analysed individually by direct sample introduction. A quartz rod with a sharp end was used to assist sample transfer. The mass of each particular sample (range 1-2 mg) was determined using a Mettler MU3 electronic microbalance. The dry mass of the sample was calculated assuming that the moisture content did not vary appreciably within each particular plant. The latter was determined on a separate sample. In plant metal- 
uptake studies a large number of tissue biopsy samples were taken in vivo from the same plant species. Identical tissue samples were combined, dried and pulverized. Generally 10-100 $\mathrm{mg}$ of dried tissue material was obtained for analysis.

Hair samples : Segments 2-4 mm in diameter were punched out at selected distances along the hair length. The exact mass of the hair material in the segment was obtained by weighing the total mass of the segment. Two typical sealed hair bundles with $4 \mathrm{~mm}$ diameter segments cut out. Accurately weighed samples were treated repeatedly with $\mathrm{HNO}_{3}$, the excess of which evaporated and made to a standard volume. Aliquots of the sample solution were used for analysis. (Table 5)

The main concern of the present study was to achieve acceptable accuracy and precision of measurements using simple aqueous standard calibration. For this purpose a number of international biological standard or certified reference materials (SRMsICRMs) and internal hair reference samples were analyzed in triplicate. The data were averaged, and the standard deviation calculated. Reference materials were suspended in twice-distilled water and $1 \mathrm{M} \mathrm{HNO}_{3}$. The mass-to-volume ratio of the suspensions varied depending on the analyte and its concentration in the reference material. The following masses of SRMsl CRMs were suspended in $1 \mathrm{ml}$ of the diluent: $25-100 \mathrm{mg}, 2.5-20 \mathrm{mg}, 10-50 \mathrm{mg}$ and $10-40 \mathrm{mg}$ for the determination of cadmium. Analyte partitioning was determined in these slurries by centrifugation (10000 rev min' for 20 min) of a homogenized suspension and filtration of the supernatant through a $0.2 \mathrm{pm}$ millipore membrane. Cadmium compounds present in these materials are much less soluble in water. However, the solubility is substantially enhanced in the presence of $1 \mathrm{M} \mathrm{HNO}_{3}$.

The results for cadmium determination in various international biological SRMsICRM and laboratoryprepared hair samples are summarized in Table 6. As no reference values were available for hair samples, these were compared by the values analyzed by neutron activation.

\section{Summary and Conclusions}

Other data obtained for botanical reference materials are reasonably within the uncertainty limits of the certified values. These intervals were in certain cases rather broad, as for example for cadmium in Citrus Leaves. In contrast, some of the reference materials were found to be homogeneous even in the sub milligram range, for example Mussel Tissue where no significant difference in cadmium values was found between aqueous and $1 \mathrm{M} \mathrm{HNO}_{3}$ slurries, despite the considerable difference in representative sample mass. The same applies for manganese determination in the ground Rye Grass sample. No feasible explanation could be proposed for the apparent difference in the measured and certified cadmium value in this material.

The data presented in these sections clearly indicate that $\mathrm{Cd}$ in micro quantities could be successfully determined by the displacement of ${ }^{*} \mathrm{Zn}$ from $\mathrm{Zn}$ : PAN. Conditions have been established for the quantitative displacement which included a detailed study of the effect of diverse ions. A linear calibration with regression coefficient 0.9982 is indicative of the success of the method.

Further, preconcentration of $\mathrm{Cd}$ by adsorbing on strong anion exchange resin, Dowex -IX-8 provides an enrichment factor of 26 and also helps in keeping the interferences suppressed for the matrices selected for the determination.

The method developed has been successfully utilized for the determination of biological, botanical and hair samples for cadmium.

Direct analysis of 2-4 $\mathrm{mm}$ hair segments employing the proposed sampling strategy enabled measurement of longitudinal concentration gradients of chromium, lead and cadmium in the hair of tannery workers, and of children (age 10 to 14) from residential areas characterized by different levels of cadmium in ambient air. These results were demonstrated to be useful in the correct interpretation of analytical data for hair chromium, lead and cadmium in terms of nutritional intake, environ- mental and occupational exposure. First proximal hair segment values provide more reliable data on true metabolic trace element incorporation than the conventionally employed average trace element contents of the whole hair length.

Analytical results obtained for biological and botanical samples are highly reproducible and compare well with the certified values.

Table.1.Analytical performance of the present method for the determination of cadmium

\begin{tabular}{|l|c|}
\hline \multicolumn{1}{|c|}{ Parameter } & Value \\
\hline Preconcentration factor & 20 \\
Detection limit $(\mu \mathrm{g})(\mathrm{n}=5)$ & 6 \\
Precision $(\% \mathrm{RSD})(\mathrm{n}=7)$ & 2.66 \\
Correlation coefficient $(\mathrm{r})$ & 0.9996 \\
\hline
\end{tabular}


Table.2.Accuracy of the analysis of cadmium in the Certified Reference Material (CRM)

\begin{tabular}{|c|c|c|c|}
\hline \multirow{2}{*}{ Sample } & \multicolumn{2}{|c|}{ Value $\left(\mu \mathrm{g} \mathrm{g}^{-1}\right)(\mathrm{n}=7)$} & \multirow{2}{*}{ Recovery, \% } \\
\cline { 2 - 3 } & certified & Found & \\
\hline $\begin{array}{c}\text { SRM 1577b } \\
\text { (Bovine liver) }\end{array}$ & 0.50 & $0.46 \pm 0.01$ & 92.0 \\
\hline
\end{tabular}

Table.3. Analysis of rice samples

\begin{tabular}{|c|l|c|}
\hline Sample & \multicolumn{1}{|c|}{ Source } & $\begin{array}{c}\text { Average } \\
\text { Cadmium content } \\
\left(\mu \mathrm{g} \cdot \mathrm{kg}^{-1}\right)^{*}\end{array}$ \\
\hline 1 & Irrigated by well water & 6.5 \\
2 & Irrigated by bore well water & 8.2 \\
3 & Irrigated by river water & 10.2 \\
4 & Nearer to industrial area & 82.2 \\
\hline
\end{tabular}

\section{*Average of 5 determinations}

Table. 4. Day-to-day (D-day) and within day (W-day) reproducibility of Cd spiked in urine

\begin{tabular}{|c|c|c|c|c|c|c|}
\hline \multirow{2}{*}{$\begin{array}{c}\text { Statistical } \\
\text { data }\end{array}$} & \multicolumn{6}{|c|}{ Cd added $(\mu \mathrm{g} / \mathrm{L})$ sample volume: $50 \mathrm{~mL}, \mathrm{~N}=6$} \\
\cline { 2 - 7 } & \multicolumn{2}{|c|}{1.0} & \multicolumn{2}{c|}{1.5} & \multicolumn{2}{c|}{2.0} \\
\cline { 2 - 7 } & D-day & W-day & D-day & W-day & D-day & W-day \\
\hline & & & & & & \\
Mean & 0.937 & 0.975 & 1.457 & 1.452 & 1.936 & 1.916 \\
$\sigma$ & 1.032 & $0 / 16$ & 0.983 & 0.830 & 1.032 & 0.83 \\
CV \% & 1.06 & 0.17 & 1.01 & 0.850 & 1.020 & 0.86 \\
& & & & & & \\
\hline
\end{tabular}

Table.5. Analyte partitioning in biological reference materials and hair

\begin{tabular}{|l|c|}
\hline \multicolumn{1}{|c|}{ Material } & Cd found $(\mu \mathrm{g})$ \\
\hline Rye Grass & 6 \\
BRC-CRM No. 28 1 & 97 \\
Oleu e iropueu & 80 \\
BRC-CRM No. 62 & 12 \\
Citrus leaves & 85 \\
NBS-SRM No. 1572 & 12 \\
Mussel Tissue & 85 \\
BRC-CRM NO. 278 & \\
Hair Internal Reference & 85 \\
Sample & \\
\end{tabular}


Fig.1. Adsorption and elution of $\mathrm{Cd}(\mathrm{II})$ on Dowex $1 \times 8$
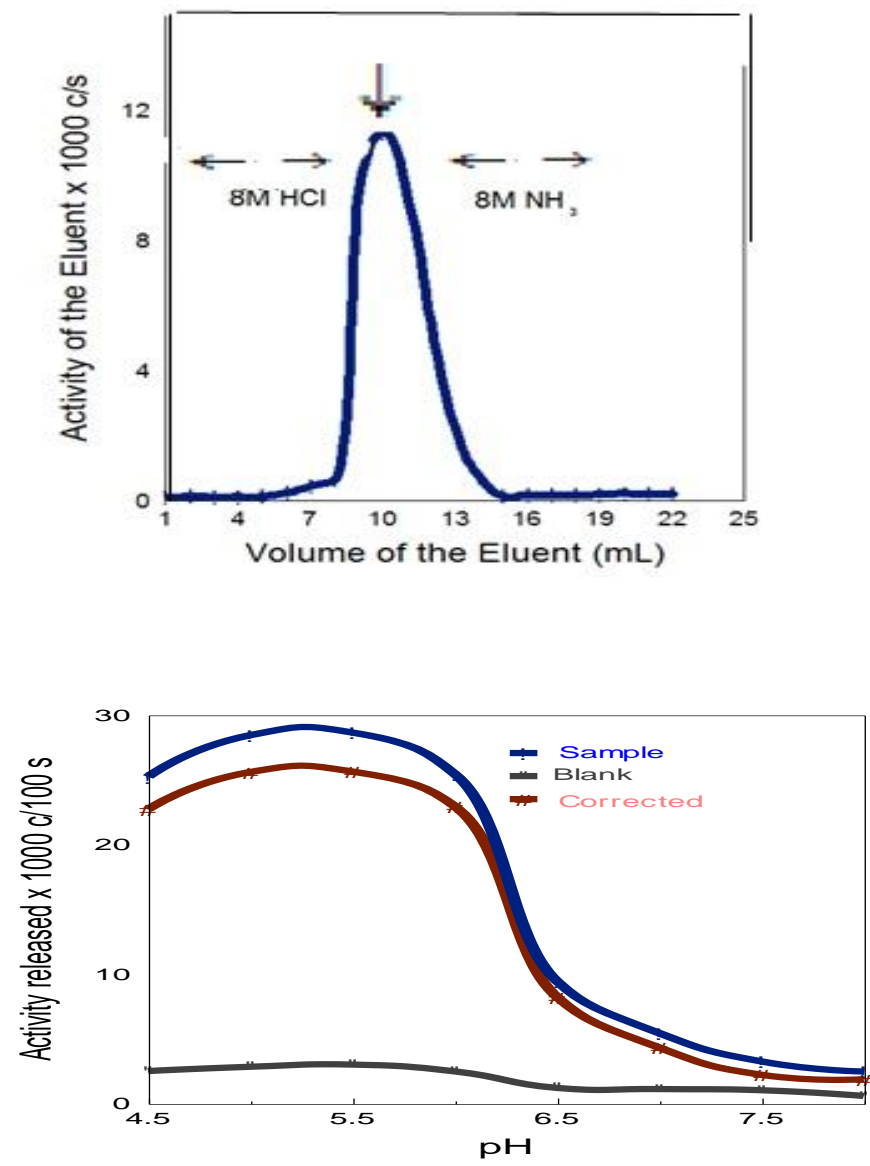

Fig.2. Effect of $\mathrm{pH}$ on the displacement reaction

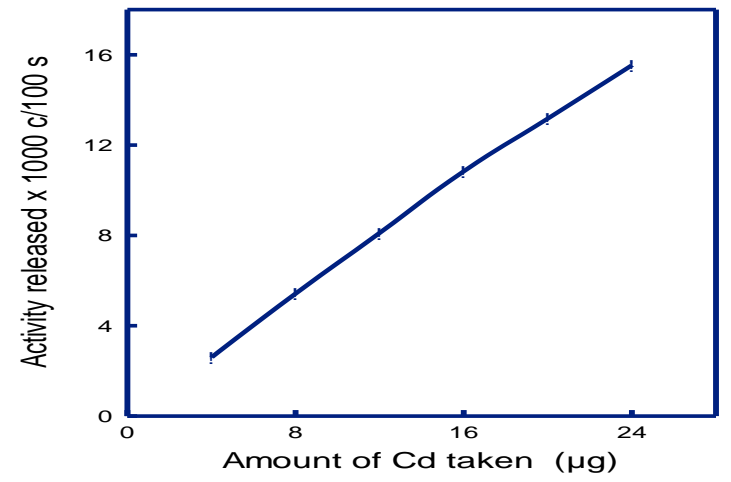

Fig.3. Calibration

\section{References}

[1.] P.S.Bedregal and E.H. Montoya, Journal of Radioanalytical and Nuclear Chemistry., 254, 363 ( 2002)

[2.] T.Kawada and S.Suzukigto, Journal of Chromatography., 150, 143, (1991).

[3.] R.Dowtali and R.E. Jervis, Journal of Radioanalytical and Nuclear Chemistry., 150, 455 ( 1991).

[4.] S.S.Aldabbgh and R.Dybczynski, Journal of Radioanalytical and Nuclear Chemistry, Articles., 92,37 (1985).

[5.] J.R.W. Woittiez, and M. De La Cruz Tangonan, Journal of Radioanalytical and Nuclear Chemistry, Articles., 158, 313 (1992).

[6.] Zbigniew Samczynski and Rajmund Dybczynski., J. Chromatography, 789, 157 (1997)

[7.] K. Aruna and B. Rangamannr, J. Radioanal. Nucl. Chem. Lett., 95, 275 (1993)

[8.] J.F. Alder, J.Samuel and T.S. West., Anal. Chim. Acta., 87,313 (1976) 